\title{
Fragmentable Heterogeneous Cocatalysts for the Metallocene-Catalyzed Polymerization of Olefins, II [1]. Preparation, Characterization and Testing of the Cocatalysts and Microscopic Evaluation of the Polyethylene
}

\author{
Herbert Schumann, Ralf Widmaier, Katharina C. H. Lange, and Birgit C. Wassermann \\ Institut für Chemie, Technische Universität Berlin, \\ Straße des 17. Juni 135, D-10623 Berlin, Germany \\ Reprint requests to Prof. Dr. H. Schumann. E-mail: Schumann@chem.tu-berlin.de
}

Z. Naturforsch. 60b, 614-626 (2005); received December 28, 2004

\begin{abstract}
Surface modified silica were reacted with different aluminiumalkyls $\mathrm{AlR}_{2} \mathrm{R}^{\prime}(\mathrm{R}=\mathrm{Me}, \mathrm{Et}, i$-Bu, $\mathrm{R}^{\prime}=\mathrm{H}, \mathrm{Me}, \mathrm{Et}, i$-Bu), oligomeric methylaluminoxane (MAO) and combinations of both, to yield heterogeneous cocatalysts. These cocatalyts were employed to polymerize ethylene using zirconocene dichloride as the catalyst. The polymerization activity profiles have been recorded and compared with the information gained from the scanning electron microscopy (SEM) images of the polymers. The fragmentation of the heterogeneous cocatalyts upon polymerization has been demonstrated. The degree of fragmentation and the polymerization activity depend on the preparation of the silica supports and on the preparation of the heterogeneous cocatalysts using these supports. The most reactive, fragmentable heterogeneous cocatalysts show polymerization activities slightly higher than MAO in homogeneous solution and almost 1.5 times higher than commercially available MAO on silica (= MAO on Sylopol).
\end{abstract}

Key words: Cocatalyst, Heterogenization, Polymerization, Catalyst, Aluminiumorganyl

\section{Introduction}

Ever since the first polymerization of ethylene using $\mathrm{Zr}(\mathrm{acac})_{4}$ as the catalyst performed by Ziegler and Breil in 1953 [2], and that of propylene by Natta [3], extensive research was carried out to improve the properties of the polymers, the production processes and - a as crucial point - the catalysts. The major breakthrough was achieved by heterogenizing $\mathrm{TiCl}_{4}$ on $\mathrm{MgCl}_{2}$ in combination with triethylaluminium (TEA) as a cocatalyst and scavenger, and introducing internal donors such as aromatic carboxylic acid esters [4a,5]. Although known and well examined in the 1950s, metallocenes like $\mathrm{Cp}_{2} \mathrm{TiCl}_{2}[4 \mathrm{a}, 6]$ became major research targets after the discovery of Reichert and Meyer in 1973, that small amounts of water (formerly considered a catalyst poison) could increase drastically the activity of the $\mathrm{Cp}_{2} \mathrm{TiEtCl} / \mathrm{Et}_{2} \mathrm{AlCl}$ system [7]. Long and Breslow found a partially hydroxylated aluminoxane to be a better activator for the metallocene than simple $\mathrm{AlR}_{3}$ [8], and Kaminsky and Sinn finally produced polymeric methylaluminoxane (MAO) by controlled hydrolysis of trimethylaluminum (TMA) [9]. The interaction of MAO with metallocenes has been thoroughly examined [10-12] and various structures of MAO have been proposed [13].

For technical applications, polymerization catalysts and/or cocatalysts have to be heterogenized to be used as drop-in catalysts for existing reactors [14]. Heterogeneous catalysts are much easier to store, transport and add into a reactor [15]. Besides the physical aspects, the chemical advantages of heterogenized systems are improved stabilization of the active metal centers during polymerization [4], control of the polymer particle-morphology $[16,17]$, and control of the polymerization activity during the process by tuning the fragmentation pattern of the catalyst support particles $[14,17,18]$.

Commercial catalysts for polymerization reactions have to fulfill specific requirements [19]: Besides the polymerization activity the heterogeneous catalyst should exert a control over the morphology of the resulting polymer particle to yield polymer powders/particles of uniform size and shape. To achieve this, the support particle and each fragment of it generated by the growing of the polymer inside the catalyst particle should replicate its morphology in the same way. Such a morphology control depends on the 
shape and stability of the support particle and thus, has to be balanced with all the other mechanical properties of the support particles (i.e. stability during transport/storage).

Heterogeneous catalysts can be prepared via numerous routes and methods [18-21]. Most importantly, any leaching of the catalytic species before and during polymerization has to be avoided in order to perform a true heterogeneous reaction. Metal complexes and macromolecules like MAO can be heterogenized by physical interactions with the support (physisorption) or by chemical bonding (chemisorption). Mechanical interactions, i.e. inclosure in a trap or cage, have also been reported. The four principal methods to heterogenize metallocenes, half sandwich, constrained geometry and other metal complexes have been summarized by Kaminsky [22]: 1) direct heterogenization of the metal complex on a solid support, 2) direct heterogenization of the pre-activated catalyst/cocatalyst mixture, 3 ) indirect heterogenization of the catalyst on a solid support already modified with the cocatalyst, and 4) heterogenization of the catalyst via chemical bonds to a spacer separating support and catalyst.

Heterogenization of aluminiumalkyls, boranes, and borates as well as the in situ generation of MAO and the use of MAO itself as a support have been reported. MAO solutions were dried, or MAO was precipitated using various precipitation aids $[17,23]$ or crosslinking agents [24, 25], and then dried. MAO and higher aluminoxanes were synthesized by hydrolysis of the respective aluminiumalkyls on water-containing supports like $\mathrm{SiO}_{2}, \mathrm{MgCl}_{2}\left(\mathrm{H}_{2} \mathrm{O}\right)_{6}, \mathrm{Mg}(\mathrm{OH})_{2}, \mathrm{Al}(\mathrm{O}) \mathrm{OH}$, zeolithes, and clays [18a, 26-29].

\section{Results and Discussion}

\section{Strategy and nomenclature of the cocatalysts}

Functional groups bearing interlinked agglomerates of surface-modified silica particles were prepared from nonporous silica spheres by reaction with various bifunctional trialkoxy(aminoorgano)silanes as spacers and various trifunctional bis(alkoxyorganosilyl) compounds as linkers to get fragmentable heterogeneous cocatalysts [1]. The second functional group in the spacers and linkers show no reaction with silica and remain intact for an interaction with aluminiumalkyls or MAO. This may occur via chemisorption forming Al-N bonds with $e$. $g$. the $-\left(\mathrm{CH}_{2}\right)_{3}-\mathrm{NH}-\left(\mathrm{CH}_{2}\right)_{3}$ - linkers (Fig. 1), via van der Waals interactions with organic chains such as $-\left(\mathrm{CH}_{2}\right)_{8}$-, via strong donor-acceptor in-
Table 1. Nomenclature of the cocatalysts.

\begin{tabular}{|c|c|c|}
\hline \multicolumn{2}{|c|}{ Compound/method } & \multirow{2}{*}{$\begin{array}{l}\text { Abbreviation } \\
\text { M250 }\end{array}$} \\
\hline Silica & Monospher 250 (Merck) & \\
\hline \multirow[t]{4}{*}{ Linker } & 1,8-Bis(triethoxysilyl)octane & $\mathrm{C} 8$ \\
\hline & Bis[(3-trimethoxysilyl)propyl]amine & $\mathrm{C} 3 \mathrm{NC} 3$ \\
\hline & $\begin{array}{l}\text { Bis[(3-dimethoxy-methyl-silyl)propyl]- } \\
\text { polypropyleneoxide }\end{array}$ & PPO \\
\hline & $\begin{array}{l}\text { Methoxy-terminated } \\
\text { polydimethylsiloxane }\end{array}$ & PDMS \\
\hline \multirow[t]{3}{*}{ Spacer } & 3-Aminopropyl-trimethoxysilane & N1 \\
\hline & $\begin{array}{l}\text { 3-(2-Aminoethylamino)propyl- } \\
\text { trimethoxysilane }\end{array}$ & $\mathrm{N} 2$ \\
\hline & $\begin{array}{l}\text { 3-[2-(2-Aminoethylamino)ethylamino]- } \\
\text { propyl-trimethoxysilane }\end{array}$ & N3 \\
\hline \multirow[t]{3}{*}{ Preparation } & without addition of water & oW \\
\hline & with addition of water & $\mathrm{mW}$ \\
\hline & $\begin{array}{l}\text { low ratio/high ratio silane/silanol } \\
\text { reverse addition: } 1 \text {. silanes, } 2 \text {. silica }\end{array}$ & $\begin{array}{l}\mathrm{nB}, \mathrm{hB} \\
\mathrm{R}\end{array}$ \\
\hline \multirow[t]{3}{*}{ Cocatalyst } & Trimethylaluminium & TMA \\
\hline & Triethylaluminium & TEA \\
\hline & Methylaluminoxane & MAO \\
\hline
\end{tabular}

Fig. 1. Interactions of the linker $-\left(\mathrm{CH}_{2}\right)_{3}-\mathrm{NH}-\left(\mathrm{CH}_{2}\right)_{3}-$ (C3NC3) with aluminium organyls forming an Al-N-bond.

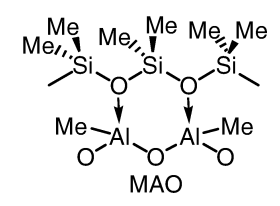

Fig. 2. Interactions of the linker $-\left[\mathrm{SiMe}_{2}-\mathrm{O}\right]-\quad$ (PDMS) with aluminium organyls. teractions $\mathrm{O} \rightarrow \mathrm{Al}$ with ether groups, or weaker coordination with $-\mathrm{Me}_{2} \mathrm{Si}-\mathrm{O}-\mathrm{SiMe}_{2}$-groups (Fig. 2).

The nomenclature of the supports follows the scheme "silica(linker)spacer(preparation)/cocatalyst" or "silica(linker)spacer(preparation)/cocatalyst/cocatalyst" (for the two-step treatement). For the abbreviations of the employed silica, linkers, spacers, cocatalysts and special procedures of the preparation see Table 1. As an example, for silica(linker)spacer(preparation)/cocatalyst/cocatalyst, first silica was reacted with the linker and the spacer under the conditions defined elsewhere [1]. The modified silica was subsequently separated and dried. This modified silica was reacted (in one step) with the cocatalyst, separated and dried. The resulting heterogeneous cocatalyst was reacted again with the same or another cocatalyst (in a second step) to yield the final product. Silica and linker and/or spacer on the left side of the slash "/" were reacted in a separate reaction, and then the reaction prod- 
uct was isolated and reacted with the compounds on the right side of the slash.

Reactions of modified silica with aluminiumorganyls: synthesis and characterization

Different modified silicas and unmodified M250 were reacted with various aluminiumalkyls and MAO, including TMA, TEA and di-iso-butylaluminium hydride (DIBAH). The silicas were reacted either in one step reactions with one of the aluminium organyls or in two step-reactions with TMA/MAO, TEA/MAO and MAO/MAO. MAO was prepared in situ by hydrolysis of TMA in a three step-reaction TMA/water/TMA. Reactions were performed under inert atmosphere by adding the aluminium organyls as liquids or as solutions in heptane or toluene to suspensions of the organosilicon-modified silicas in toluene or heptane. Suspensions were refluxed and vigorously stirred for several hours, then filtered using a custom-made apparatus with a Teflon membrane of $200 \mathrm{~nm}$ pore size as the filter. The residue was washed several times with toluene and hexane or pentane to ensure that only truly heterogenized aluminium organyl was left on the silica. Owing to this procedure, leaching of the aluminium organyl during polymerization could be ruled out as proven by leaching tests. Characterization of the heterogeneous cocatalysts was attempted by microscopic and ${ }^{27} \mathrm{Al}$ solid state NMR investigations. Both techniques showed limitations and were performed only on two samples for each technique. Atomic absorption spectroscopy (AAS) served as the main tool to determine the amount of aluminium in the solid heterogeneous cocatalysts.

\section{Aluminiumalkyl-modified silica}

All reactions of aluminiumalkyls with aminoalkylfunctionalized silica (spacer-modified silica) were exothermic and showed evolution of hydrocarbons. Table 2 lists all reactions performed in the study.

The maximum aluminium content achieved was $2.06 \mathrm{mmol} \mathrm{Al} / \mathrm{g}$ (determined by Al-AAS), whereas the maximum nitrogen content (determined by combustion elemental analysis) was $3.4 \mathrm{mmol} \mathrm{N} / \mathrm{g}$. It was only in the case of M250N3(oW)/TMA that $95 \%$ of the $\mathrm{N}$-atoms could be functionalized $(2 \mathrm{mmol} \mathrm{Al} / \mathrm{g}$ and $2.07 \mathrm{mmol} \mathrm{N} / \mathrm{g}$ ), all other compounds showed a lower degree of functionalization. Diffusion and pore-size limitations play no role with M250 spheres, but the formation of thick layers of polyorganosilane may restrict
Table 2. Reactions of aluminiumalkyls with aminoalkylfunctionalized silica.

\begin{tabular}{llccc}
\hline \multicolumn{3}{l}{ Silica gel Spacer Preparation } & $\begin{array}{c}\text { Functionalization with } \\
\text { aluminiumorganyl }\end{array}$ & $\begin{array}{c}\text { Loading of Al } \\
{[\mathrm{mmol} / \mathrm{g}]}\end{array}$ \\
\hline M250 & N1 & MW & TEA & 1.0 \\
M250 & N2 & mW & TMA & 1.6 \\
M250 & N3 & mW & TMA & 2.6 \\
M250 & N3 & mW & TEA & 2.5 \\
M250 & N3 & mW & DIBAH & 1.3 \\
M250 & N3 & oW & TMA & 2.0 \\
M250 & N3 & oW,R & TMA & 2.5 \\
\hline
\end{tabular}

the functionalization of amine groups of the particles. Alternatively, bulky $\mathrm{N}$-AlR 2 -groups may block other $\mathrm{NH}$-groups from reacting with $\mathrm{AlR}_{3}$. Donor/acceptor interactions of one or two $\mathrm{N}-\mathrm{AlR}_{2}$-groups on one spacer arm may lower the reactivity of the second and/or the third NH-group in the same spacer arm and the $\mathrm{Al}$ atom may become chelated (Fig. 3).

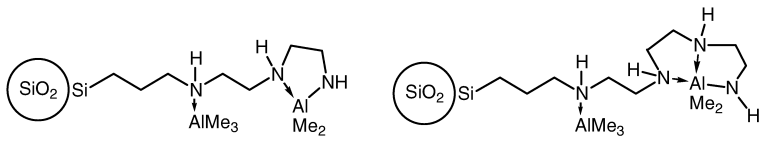

Fig. 3. Aminoalkyl-functionalized silica: Proposed interactions of $\mathrm{NH}$-groups with $\mathrm{AlMe}_{3}$ and $\mathrm{N}-\mathrm{AlMe}_{2}$-groups.

Unfortunately, neither ${ }^{27} \mathrm{Al}$ solid state NMR spectra nor TEM images of the products provided additional informations regarding the reason for the lower than expected degree of functionalization.

\section{MAO-modified silica}

The most important cocatalyst for the metallocenecatalyzed olefin polymerization is MAO. Interactions of MAO with a support may be purely steric, i.e. by inclusion within a net or in cavities, by physisorption like van der Waals or donor-acceptor interactions, and by chemical bonding (chemisorption). Commercial MAO contains some absorbed TMA, which provides enhanced reactivity. Therefore the supports were grafted deliberately with MAO which had previously been reacted with TMA.

\section{Cocatalysts on silica containing the C3NC3-linker}

The amino group in the spacer-/linker-modified silicas is very useful for grafting of aluminiumalkylcontaining compounds: The reaction results in the formation of Al-N-bonds. Three of the supports employed were based on $\mathrm{C} 3 \mathrm{NC} 3 / \mathrm{N} 1$ and differed only in the amount of water which 


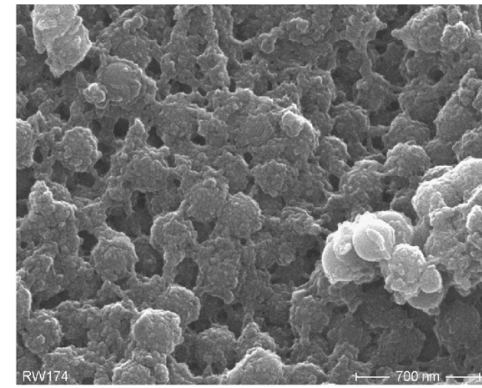

a)

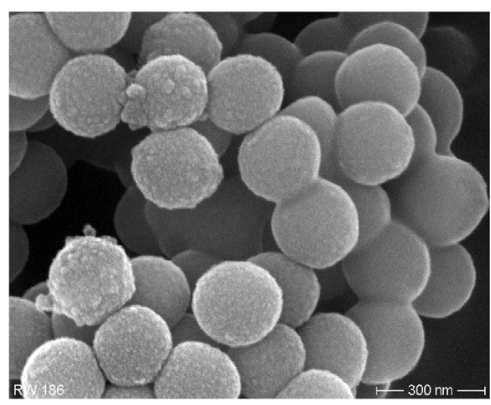

b)

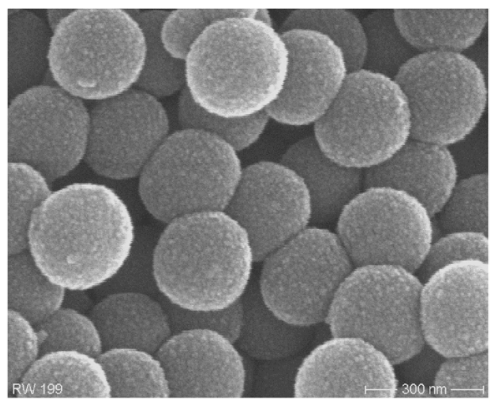

c)

Fig. 4. SEM-images of a) M250(C3NC3)N1(mW)A (45000×), b) M250(C3NC3)N1(mW)B (90000×) and c) M250(C3 NC3)N1(mW)C (100000× magnification).

had been used in the surface-modification reaction of M250: M250(C3NC3)N1(mW)A/MAO, $\mathrm{M} 250(\mathrm{C} 3 \mathrm{NC} 3) \mathrm{N} 1(\mathrm{~mW}) \mathrm{B} / \mathrm{MAO}$ and $\mathrm{M} 250(\mathrm{C} 3 \mathrm{NC} 3)$ $\mathrm{N} 1(\mathrm{~mW}) \mathrm{C} / \mathrm{MAO}$ (A, B and $\mathrm{C}$ are designating different stoichiometries). Two other supports were prepared without adding water to the reaction mixture: $\mathrm{M} 250(\mathrm{C} 3 \mathrm{NC} 3) \mathrm{N} 1(\mathrm{hB}) / \mathrm{MAO}$ and $\mathrm{M} 250(\mathrm{C} 3 \mathrm{NC} 3) \mathrm{N} 1$ (oW)/MAO.

Although the differences of the ratio silanol:spacer: linker:water (water adsorbed on the silica - resulting from the drying procedure - plus added water) were large and the number of NH-groups differed, the amount of aluminium found on M250(C3NC3) $\mathrm{N} 1(\mathrm{oW}) / \mathrm{MAO}$ (2.64 $\mathrm{mmol} \mathrm{Al} / \mathrm{g}$ ) was larger than that found on $\mathrm{M} 250(\mathrm{C} 3 \mathrm{NC} 3) \mathrm{N} 1(\mathrm{hB}) / \mathrm{MAO}$ (2.53 mmol $\mathrm{Al} / \mathrm{g})$. This is very likely due to the different spacer: linker ratios.

The cocatalysts M250(C3NC3)N1(mW)A/MAO, $\mathrm{M} 250(\mathrm{C} 3 \mathrm{NC} 3) \mathrm{N} 1(\mathrm{~mW}) \mathrm{B} / \mathrm{MAO}$ and $\mathrm{M} 250(\mathrm{C} 3 \mathrm{NC} 3)$ $\mathrm{N} 1(\mathrm{~mW}) \mathrm{C} / \mathrm{MAO}$ show higher contents of Al. There is no obvious correlation between the amount of water used for the preparation of the supports plus the amount of water found in the cocatalyst and the amount of aluminium in the product. SEM images of $\mathrm{M} 250(\mathrm{C} 3 \mathrm{NC} 3) \mathrm{N} 1(\mathrm{~mW}) \mathrm{A}$ revealed a strongly modified surface: the silica spheres were completely covered with organopolysiloxane. With a large number of $\mathrm{NH}$-groups present for binding $\mathrm{MAO}$, this results in a large Al-content. The supports M250(C3NC3)N1(mW)B and M250(C3NC3) $\mathrm{N} 1(\mathrm{~mW}) \mathrm{C}$ showed only a fairly modified silica surface with little or very little organopolysiloxane, respectively. Consequently, similar amounts of MAO were grafted on the supports resulting in similar Al-contents (2.76 and 2.86, respectively).
It can thus be concluded that the amount of MAO grafted onto the supports via $\mathrm{NH}$-groups is dependent on the amount of functional groups. Primary amines as in $\mathrm{N} 1$ are more easily accessible than secondary amines as in $\mathrm{C} 3 \mathrm{NC} 3, \mathrm{~N} 2$ or $\mathrm{N} 3$. The accessibility depends also on the morphology of the modified silica supports: Due to the large excess of organopolysiloxane on M250(C3NC3)N1(mW)A, many more $\mathrm{NH}$-groups are accessible (note the large surface due to "arms" and "fingers" in Fig. 4), whereas this number is smaller in M250(C3NC3)N1(mW)B and $\mathrm{M} 250(\mathrm{C} 3 \mathrm{NC} 3) \mathrm{N} 1(\mathrm{~mW}) \mathrm{C}$.

The Al-content of M250(C3NC3)N1(mW)C/MAO is estimated to be $2.75 \mathrm{mmol} \mathrm{Al} / \mathrm{g}$. M250(C3NC3)N1 (oW) shows a lower $\mathrm{N}$-content of $0.92 \mathrm{mmol}$ $\mathrm{N} / \mathrm{g}$ as compared M250(C3NC3)N1(mW)B with $2.12 \mathrm{mmol} \mathrm{N} / \mathrm{g}$, but only slightly different Al-contents (M250(C3NC3)N1(oW)/MAO (2.64 mmol Al/g), $\mathrm{M} 250(\mathrm{C} 3 \mathrm{NC} 3) \mathrm{N} 1(\mathrm{~mW}) \mathrm{B} / \mathrm{MAO}(2.76 \mathrm{mmol} \mathrm{Al} / \mathrm{g})$ ). For comparison, M250(C3NC3)N1(mW)C/MAO has $2.84 \mathrm{mmol} \mathrm{Al} / \mathrm{g}$.

For the preparation of $\mathrm{M} 250(\mathrm{C} 3 \mathrm{NC} 3) \mathrm{N} 3(\mathrm{~mW})$ the suspension of silica in toluene was saturated with water by purging water-containing nitrogen gas through the suspension. The resulting support consisted of very evenly modified silica spheres and showed an $\mathrm{N}$-content of $11.74 \%$ compared to $11.99 \%$ for $\mathrm{M} 250(\mathrm{C} 3 \mathrm{NC} 3) \mathrm{N} 1(\mathrm{~mW}) \mathrm{A}$. After reacting both with $\mathrm{MAO}$, the Al-contents of the products were almost the same: 4.21 and $4.20 \mathrm{mmol} \mathrm{Al/g}$, respectively.

The combinations of the amine-containing spacers N1 and N3 with the aminolinker C3NC3 showed the expected correlation between the Al-content of the cocatalyst and the preparative procedures of the corresponding supports as defined by a) the 
amount of water, the mode and evenness of its addition to the suspended silica, and b) the ratios silanol:linker:spacer:water. a) and b) define the amount of functional groups on the supports and the morphology (and thus the accessibility of the FG) of the supports. The amount of FG and the morphology of the support finally define the amount of MAO grafted onto the support.

\section{Cocatalysts on silica containing the C8-linker}

Four different cocatalysts using the all-alkyl-linker C8 were prepared. The amount of MAO grafted increases with increasing amount of C8 on the support. Thus, upon using more water for the support preparation the MAO content increased by $56 \%$ on going from $\mathrm{M} 250(\mathrm{C} 8)(\mathrm{oW}) / \mathrm{MAO}$ to $\mathrm{M} 250(\mathrm{C} 8)(\mathrm{mW}) / \mathrm{MAO}$.

In the preparations with the spacer $\mathrm{N} 1$ the different reactivities of the silanes $\mathrm{C} 8$ and $\mathrm{N} 1$ in the reaction with silica must be taken into account: In the presence of small amounts of water N1 is far more reactive towards condensation with the silanol surface on silica than C8 due to autocatalysis [30]. Consequently, when small amounts of water were employed with $\mathrm{M} 250(\mathrm{C} 8) \mathrm{N} 1(\mathrm{oW})$, the amount of N1 relative to $\mathrm{C} 8$ on the support is higher $(0.48 \mathrm{mmol} \mathrm{N} / \mathrm{g})$ than for larger amounts of water in $\mathrm{M} 250(\mathrm{C} 8) \mathrm{N} 1(\mathrm{hB})$ (0.34 mmol N/g). M250(C8)N1(oW)/MAO (1.4 mmol $\mathrm{Al} / \mathrm{g}$ ) therefore showed a higher $\mathrm{Al}$-content than $\mathrm{M} 250(\mathrm{C} 8) \mathrm{N} 1(\mathrm{hB}) / \mathrm{MAO}(0.88 \mathrm{mmol} \mathrm{Al} / \mathrm{g})$. Because of the obvious complexity of the system, the work on C8containing cocatalysts was terminated.

\section{Cocatalysts on silica containing the PPO-linker}

The PPO-containing cocatalysts suffered from a similar complexity like the C8-containing cocatalysts. PPO as a linker with six or seven oxygen donor centers for aluminium acceptors gave rise to relatively large Al-contents $(2.93 \mathrm{mmol} \mathrm{Al} / \mathrm{g}$ for $\mathrm{M} 250(\mathrm{PPO})(\mathrm{oW}) / \mathrm{MAO}$, which further increased to $3.61 \mathrm{mmol} \mathrm{Al/g}$ when using more $\mathrm{PPO}$ as in $\mathrm{M} 250(\mathrm{PPO})(\mathrm{mW}) / \mathrm{MAO})$. The advantage of using only PPO is that no ether cleavage reactions with MAO take place.

Although the reactivities of PPO and N1 towards condensation with the silanol surface are very much in favor of $\mathrm{N} 1, \mathrm{PPO} / \mathrm{N} 1$ is a promising combination, because PPO can bind MAO effectively without deactivating the Al-centers of MAO only by forming O-Aldonor - acceptor-bonds.

\section{Cocatalysts on silica containing the PDMS-linker}

Linear polysiloxanes PDMS provide large chain lengths between the anchoring groups. For a low silanol: PDMS ratio of 0.187 eq. in M250(PDMS)(nB), about $80 \%$ of the silanols are left unreacted and are able to react with $\mathrm{MAO}$ in the preparation of M250(PDMS)(nB)/MAO. The Al-content of this cocatalyst is $2.6 \mathrm{mmol} \mathrm{Al} / \mathrm{g}$ and therefore much larger than with M250/MAO (0.74 mmol Al/g). Small amounts of PDMS thus cause a large difference compared to unmodified M250. MAO is considered to be grafted onto the support mainly due to interactions with PDMS. Chemisorption onto the silica surface is probably of minor importance. The cocatalyst M250(PDMS)(oW)/MAO with a larger ratio silanol:PDMS of 1:1 had an Al-content of $3 \mathrm{mmol}$ $\mathrm{Al} / \mathrm{g}$. Complimentary experiments showed that, surprisingly, much of the silanes employed seem not to react with silica as shown by lower Al-contents. It therefore appears that PDMS is most effective in grafting MAO when used as the sole silane and in small amounts.

\section{Comparison of linker/spacer combinations}

Among the linker-modified supports the PPOmodified cocatalysts M250(PPO)(oW)/MAO and $\mathrm{M} 250(\mathrm{PPO})(\mathrm{mW}) / \mathrm{MAO}$ as well as the PDMScontaining M250(PDMS)(oW)/MAO showed the highest Al-contents with a maximum for the spacer/ linker-combinations $\mathrm{C} 3 \mathrm{NC} 3 / \mathrm{N} 1$ and $\mathrm{C} 3 \mathrm{NC} 3 / \mathrm{N} 3$. $\mathrm{PPO}$ alone and in combination with $\mathrm{N} 1$ is a promising linker for the preparation of heterogeneous cocatalysts, although the control of the desired PPO:N1-ratio is not trivial. Combinations of the amino-linker C3NC3 with the amino-spacers $\mathrm{N} 1, \mathrm{~N} 2$ or $\mathrm{N} 3$ are easiest to control, due to their similar reactivity towards condensation with silanols. The ratios linker:spacer and silanol:linker:spacer:water can readily be predetermined in a wide range.

Modification of supports in two step-reactions with $\mathrm{AlR}_{3} / \mathrm{MAO}$ and $M A O / M A O$

\section{$\mathrm{AlR}_{3} / \mathrm{MAO}$}

For improved performance, the amino-functional supports were modified in two consecutive reaction steps. Table 3 lists the products of this procedure.

The Al-contents of the $\mathrm{AlR}_{3} / \mathrm{MAO}$-modified aminolinker-containing cocatalysts were slightly or much 


\begin{tabular}{|c|c|c|c|c|}
\hline Cocatalyst & Support & $\begin{array}{l}\text { Cocatalys } \\
\text { componen }\end{array}$ & $\begin{array}{l}\text { Loading } \\
\text { of } \mathrm{Al} \\
{[\mathrm{mmol} / \mathrm{g}]}\end{array}$ & $\begin{array}{l}\text { Table } 3 \text {. Modification of supports in the } \\
\text { two step-reaction with } \mathrm{AlR}_{3} \text { and MAO. }\end{array}$ \\
\hline$\overline{\mathrm{M} 250 \mathrm{~N} 3(\mathrm{oW}) / \mathrm{TMA}}$ & M250N3(oW) & TMA & 2.0 & a The numbers in brackets in the column \\
\hline M250N3(oW)/TMA/MAO & M250N3(oW)/TMA & MAO & $5.90^{\mathrm{b}}$ & "loading of $\mathrm{Al}$ " are the Al-contents of the \\
\hline M250(C3NC3)N1(mW)A/TEA & $\mathrm{M} 250(\mathrm{C} 3 \mathrm{NC} 3) \mathrm{N} 1(\mathrm{~mW}) \mathrm{A}$ & TEA & 1.04 & cocatalysts prepared from the same supports \\
\hline M250(C3NC3)N1(mW)A/TEA/MAO & $\mathrm{M} 250(\mathrm{C} 3 \mathrm{NC} 3) \mathrm{N} 1(\mathrm{~mW}) \mathrm{A} / \mathrm{TE} A$ & A MAO & $4.27(4.21)^{\mathrm{a}}$ & when modified with MAO in a one step \\
\hline $\mathrm{M} 250(\mathrm{C} 3 \mathrm{NC} 3) \mathrm{N} 3(\mathrm{~mW}) / \mathrm{TEA}$ & $\mathrm{M} 250(\mathrm{C} 3 \mathrm{NC} 3) \mathrm{N} 3(\mathrm{~mW})$ & TEA & 1.61 & reaction; $b$ for $\mathrm{M} 250 \mathrm{~N} 3(\mathrm{oW}) / \mathrm{TMA} / \mathrm{MAO}$ \\
\hline $\mathrm{M} 250(\mathrm{C} 3 \mathrm{NC} 3) \mathrm{N} 3(\mathrm{~mW}) / \mathrm{TEA} / \mathrm{MAO}$ & $\mathrm{M} 250(\mathrm{C} 3 \mathrm{NC} 3) \mathrm{N} 3(\mathrm{~mW}) / \mathrm{TEA}$ & MAO & $5.52(4.20)^{\mathrm{a}}$ & there is no $\mathrm{M} 250 \mathrm{~N} 3(\mathrm{oW}) / \mathrm{MAO}$ as a ref- \\
\hline $\mathrm{M} 250(\mathrm{PPO}) \mathrm{N} 1(\mathrm{hB}) / \mathrm{TEA}$ & M250(PPO)N1(hB) & TEA & 0.385 & erence; only $\mathrm{M} 250 \mathrm{~N} 3(\mathrm{~mW}) / \mathrm{MAO}$ was in- \\
\hline $\mathrm{M} 250(\mathrm{PPO}) \mathrm{N} 1(\mathrm{hB}) / \mathrm{TEA} / \mathrm{MAO}$ & M250(PPO)N1(hB)/TEA & MAO & $2.39(2.68)^{\mathrm{a}}$ & cluded $(3.79 \mathrm{mmol} \mathrm{Al} / \mathrm{g})$ \\
\hline
\end{tabular}

higher than those of the MAO-modified systems. When reacted with TEA/MAO, the PPO/N1 cocatalyst shows a lower Al-content than the MAO-modified cocatalyst based on the same support. The aluminiumalkyls TMA and TEA react similarly probably laeving only donor groups for the subsequent reaction with MAO.

The support M250(PPO)N1(hB) which has only a low $\mathrm{N}$-content shows after the reaction with TEA a corresponding low Al-content of $0.385 \mathrm{mmol} \mathrm{Al} / \mathrm{g}$. In the second reaction step with MAO the amount of MAO grafted led to a loading of approx. $2 \mathrm{mmol} \mathrm{Al} / \mathrm{g}$, but the cocatalyst is almost inactive. TEA thus seems to be unsuitable for increasing the Al-content of PPOcontaining cocatalysts in the two step process with TEA/MAO. However, TMA/MAO does increase the polymerization activity of $\mathrm{C} 3 \mathrm{NC} 3$-containing cocatalysts compared to simply MAO-modified cocatalysts.

\section{MAO/MAO}

When $\mathrm{M} 250(\mathrm{C} 3 \mathrm{NC} 3) \mathrm{N} 3(\mathrm{~mW}) / \mathrm{MAO}$ is further modified with $\mathrm{MAO}$ in a second reaction step to obtain $\mathrm{M} 250(\mathrm{C} 3 \mathrm{NC} 3) \mathrm{N} 3(\mathrm{~mW}) / \mathrm{MAO} / \mathrm{MAO}$, the Alcontent increases by $45 \%$ to $6.07 \mathrm{mmol} \mathrm{Al} / \mathrm{g}$, yielding the highest Al-content achieved in this study. Despite of this large Al-content the cocatalyst is less active than $\mathrm{M} 250(\mathrm{C} 3 \mathrm{NC} 3) \mathrm{N} 3(\mathrm{~mW}) / \mathrm{MAO}$ and even less active than $\mathrm{M} 250(\mathrm{C} 8) \mathrm{N} 1(\mathrm{hB}) / \mathrm{MAO}$, which is the cocatalyst with the lowest Al-content $(0.88 \mathrm{mmol} \mathrm{Al} / \mathrm{g})$. $\mathrm{M} 250$ (PPO)N1(oW)/MAO/MAO also shows an increase of the Al-content by $72 \%$ and an increase in polymerization activity by more than $20 \%$ compared to $\mathrm{M} 250(\mathrm{PPO}) \mathrm{N} 1(\mathrm{oW}) / \mathrm{MAO}$. The main reason for these differences appears to be structural: MAO of the first layer (MAO1) is an excellent linker for MAO of the second layer (MAO2) by shielding it effectively from the influences of the linkers PPO or C3NC3 and spacers N1 or N3. TEA as a first layer is less effective.

In $\mathrm{M} 250(\mathrm{C} 3 \mathrm{NC} 3) \mathrm{N} 3(\mathrm{~mW}) / \mathrm{MAO} / \mathrm{MAO}$ the support contains too many amino groups which re- act with MAO and lower its activity. Since PPO in $\mathrm{M} 250(\mathrm{PPO}) \mathrm{N} 1(\mathrm{oW}) / \mathrm{MAO} / \mathrm{MAO}$ forms only $\mathrm{O} \rightarrow \mathrm{Al}$ donor-acceptor bonds, M250(PPO)N1(oW)/ $\mathrm{MAO} / \mathrm{MAO}$ qualifies as the most active cocatalyst of all double-modified supports.

\section{Unmodified M250 as a support for cocatalysts}

For comparison with the cocatalysts based on modified silica, unmodified M250 was reacted with MAO (M250/MAO) and MAO/MAO (M250/MAO/MAO) (one-step and two-step reactions). In the second reaction the Al-content increased from 0.74 to $2.75 \mathrm{mmol}$ $\mathrm{Al} / \mathrm{g}$. Whereas M250/MAO is only slightly active, $\mathrm{M} 250 / \mathrm{MAO} / \mathrm{MAO}$ showed medium activity. The direct reaction of MAO with unmodified M250 is a cheap alternative to use spacer-/linker-modified silica, but has its drawbacks: For a chosen silica, water (in the silica) is the only variable in the reaction. Grafting can only occur via chemical bonds to silanols or donoracceptor-bonds to siloxane-bridges. Thus, there is a high danger of leaching due to insufficient grafting.

\section{Leaching tests}

To check the strength of the grafting, leaching tests were performed. Very low leaching of grafted MAO as observed for the cocatalysts based on modified supports clearly demonstrates the advantage of the strategy (see Experimental Section).

\section{Polymerization activity}

All cocatalysts were tested in the polymerization of ethylene using $\mathrm{Cp}_{2} \mathrm{ZrCl}_{2}$ as catalyst and TIBA as scavenger. $\mathrm{Cp}_{2} \mathrm{ZrCl}_{2}$ was heterogenized in situ just before polymerization by stirring the catalyst and the cocatalyst in toluene. The slurry was then injected into the reactor and the ethylene pressure increased to 2 bar. The results are listed in Table 4. A comprehensive discussion of the results for all heterogeneous cocatalysts 


\begin{tabular}{|c|c|c|c|}
\hline Cocatalyst & Activity $^{\mathrm{a}}$ & $\begin{array}{l}\text { Al:Zr-ratio } \\
\text { [mol:mol] }\end{array}$ & $\begin{array}{l}\text { Loading of Al } \\
{[\mathrm{mmol} / \mathrm{g}]}\end{array}$ \\
\hline$\overline{\mathrm{M} 250(\mathrm{C} 3 \mathrm{NC} 3) \mathrm{N} 1(\mathrm{~mW}) \mathrm{C} / \mathrm{MAO}}$ & 63300 & $2200: 1$ & 2.84 \\
\hline MAO (homogeneous, for comparison) & 62200 & 2200:1 & \\
\hline $\mathrm{M} 250(\mathrm{PPO}) \mathrm{N} 1(\mathrm{oW}) / \mathrm{MAO} / \mathrm{MAO}$ & 45000 & 2300: 1 & 5.70 \\
\hline Sylopol/MAO (Witco) & 43900 & 2200:1 & 8.9 \\
\hline \multirow[t]{2}{*}{$\mathrm{M} 250(\mathrm{C} 3 \mathrm{NC} 3) \mathrm{N} 1(\mathrm{~mW}) \mathrm{B} / \mathrm{MAO}$} & 33500 & 2300:1 & 2.76 \\
\hline & 8900 & 1100:1 & \\
\hline M250/MAO/MAO & 30900 & 2300:1 & 2.75 \\
\hline M250(PDMS)(nB)/MAO & 26800 & 2200:1 & 2.66 \\
\hline \multirow[t]{2}{*}{$\mathrm{M} 250(\mathrm{PPO}) \mathrm{N} 1(\mathrm{hB}) / \mathrm{MAO}$} & 26800 & 2300:1 & 2.68 \\
\hline & 10500 & 1400:1 & \\
\hline \multirow[t]{2}{*}{$\mathrm{M} 250(\mathrm{C} 3 \mathrm{NC} 3) \mathrm{N} 3(\mathrm{~mW}) / \mathrm{TEA} / \mathrm{MAO}$} & 22500 & $2200: 1\left(\mathrm{Al}_{\text {total }}\right)$ & 5.52 \\
\hline & 22100 & 2300:1 (Al $\left.\mathrm{MAO}_{\mathrm{M}}\right)$ & $3.90(\mathrm{MAO})$ \\
\hline $\mathrm{M} 250(\mathrm{C} 3 \mathrm{NC} 3) \mathrm{N} 1(\mathrm{oW}) / \mathrm{MAO}$ & 22000 & $2200: 1$ & 2.64 \\
\hline M250(PPO)N1(oW)/MAO & 20300 & 2200:1 & 3.32 \\
\hline $\mathrm{M} 250 \mathrm{~N} 3(\mathrm{~mW}) / \mathrm{MAO}$ & 20200 & 2300:1 & 3.79 \\
\hline $\mathrm{M} 250 \mathrm{~N} 1(\mathrm{~mW}) / \mathrm{MAO}$ & 18400 & 2300:1 & 2.6 \\
\hline $\mathrm{M} 250(\mathrm{C} 3 \mathrm{NC} 3) \mathrm{N} 1(\mathrm{~mW}) \mathrm{A} / \mathrm{MAO}$ & 17600 & 2300:1 & 4.21 \\
\hline $\mathrm{M} 250(\mathrm{C} 8)(\mathrm{oW}) / \mathrm{MAO}$ & 16000 & 2300:1 & 1.15 \\
\hline M250(PDMS)(oW)/MAO & 16000 & 2300:1 & 3.00 \\
\hline M250/MAO/MAO(wash) & 15300 & 2200:1 & 2.48 \\
\hline M250(PPO)(oW)/MAO & 14500 & 2200:1 & 2.93 \\
\hline $\mathrm{M} 250(\mathrm{C} 8) \mathrm{N} 1(\mathrm{hB}) / \mathrm{MAO}$ & 12600 & 2200:1 & 0.883 \\
\hline $\mathrm{M} 250(\mathrm{C} 3 \mathrm{NC} 3)(\mathrm{oW}) / \mathrm{MAO}$ & 12500 & $2200: 1$ & 1.55 \\
\hline \multirow{2}{*}{ M250N3(oW)/TMA/MAO(wash) } & 12700 & $2300: 1\left(\mathrm{Al}_{\mathrm{MAO}}\right)$ & $3.71(\mathrm{MAO})$ \\
\hline & 10300 & $2200: 1\left(\mathrm{Al}_{\text {total }}\right)$ & 5.70 \\
\hline \multirow[t]{2}{*}{ M250(C3NC3)N1(mW)A/TEA/MAO } & 13900 & $2200: 1\left(\mathrm{Al}_{\text {total }}\right)$ & 4.27 \\
\hline & 12500 & $2200: 1\left(\mathrm{Al}_{\mathrm{MAO}}\right)$ & 3.23 (MAO) \\
\hline M250N3(oW)/TMA/MAO & 11800 & $2200: 1$ & 5.90 \\
\hline $\mathrm{M} 250(\mathrm{C} 8)(\mathrm{mW}) / \mathrm{MAO}$ & 11700 & 2200:1 & 1.79 \\
\hline M250(PPO)N1(mW)/MAO & 10300 & $2200: 1\left(\mathrm{Al}_{\text {total }}\right)$ & 3.12 \\
\hline $\mathrm{M} 250(\mathrm{C} 3 \mathrm{NC} 3) \mathrm{N} 3(\mathrm{~mW}) / \mathrm{MAO} / \mathrm{MAO}$ & 9700 & $2200: 1\left(\mathrm{Al}_{\text {total }}\right)$ & 6,07 \\
\hline M250/MAO & 6500 & 2300:1 & 0.7 \\
\hline M250(PDMS)N1(nB)/MAO & 5500 & 2300:1 & 2.20 \\
\hline $\mathrm{M} 250(\mathrm{PPO})(\mathrm{mW}) / \mathrm{MAO}$ & 4900 & 2200:1 & 3.61 \\
\hline M250(C3NC3)N1(hB)/MAO & 2200 & 2300:1 & 2.53 \\
\hline $\mathrm{M} 250(\mathrm{C} 3 \mathrm{NC} 3) \mathrm{N} 3(\mathrm{~mW}) / \mathrm{MAO}$ & 2100 & 2200:1 & 4.20 \\
\hline $\mathrm{M} 250(\mathrm{C} 8) \mathrm{N} 1(\mathrm{oW}) / \mathrm{MAO}$ & 1200 & 2300:1 & 1.42 \\
\hline M250(PPO)N1(hB)/TEA/MAO & 1200 & 2200:1 & 2.39 \\
\hline $\mathrm{M} 250(\mathrm{C} 3 \mathrm{NC} 3)(\mathrm{mW}) / \mathrm{MAO}$ & 800 & $2200: 1(2 \mathrm{~h})$ & 1.07 \\
\hline $\mathrm{M} 250(\mathrm{C} 3 \mathrm{NC} 3) \mathrm{N} 3(\mathrm{~mW}) / \mathrm{TEA}$ & 0 & $2200: 1$ & 1.61 \\
\hline
\end{tabular}

Table 4. Polymerization results (Polymerization temperature $30^{\circ} \mathrm{C}$ ).

a Activity in

[kg PE/mol(Zr) c(ethylene) h]. of this work is given elsewhere [31]. The main results are described here.

The most active heterogeneous cocatalyst is $\mathrm{M} 250(\mathrm{C} 3 \mathrm{NC} 3) \mathrm{N} 1(\mathrm{~mW}) \mathrm{C} / \mathrm{MAO}$, which exceeded slightly $(102 \%)$ the activity of MAO in homogeneous solution (100\%), and also the activity of the commercially available heterogeneous cocatalyst Sylopol/MAO (Witco; $8.9 \mathrm{mmol} \mathrm{Al} / \mathrm{g}$; Sylopol 2104 from Grace; 280-355 $\mathrm{m}^{2} / \mathrm{g}$ surface; $1,5-2 \mathrm{ml} / \mathrm{g}$ pore volume; $50 \mu \mathrm{m}$ medium particle size; $70,6 \%$ activity compared to homogeneous $\mathrm{MAO})$ by $45 \%$. The polymer produced with $\mathrm{M} 250(\mathrm{C} 3 \mathrm{NC} 3) \mathrm{N} 1(\mathrm{~mW}) \mathrm{C} / \mathrm{MAO}$ exhibits desirable properties (m.p. $136.8{ }^{\circ} \mathrm{C}$; $\mathrm{Mw}=708 \mathrm{~kg} / \mathrm{mol}$;
$\mathrm{Mw} / \mathrm{Mn}=2.2$ ). The second best of the new cocatalyst series, M250(PPO)N1(oW)/MAO/MAO, is still slightly more active $(72.3 \%$ related to homogeneous MAO) than Sylopol/MAO (70.6\%).

The enormous differences in polymerization activity shown in Table 4 mainly result from the morphology and the chemical structure on the surface as well as from the way of grafting the active species onto the modified supports. The Al-content in the cocatalyst has no important influence on the activity and the structure of the cocatalyst is the dominating factor. Among the three cocatalysts prepared using the same linker (C3NC3) and spacer (N1) and the same silanol:linker:spacer ratio $(1: 5: 15)$, but 


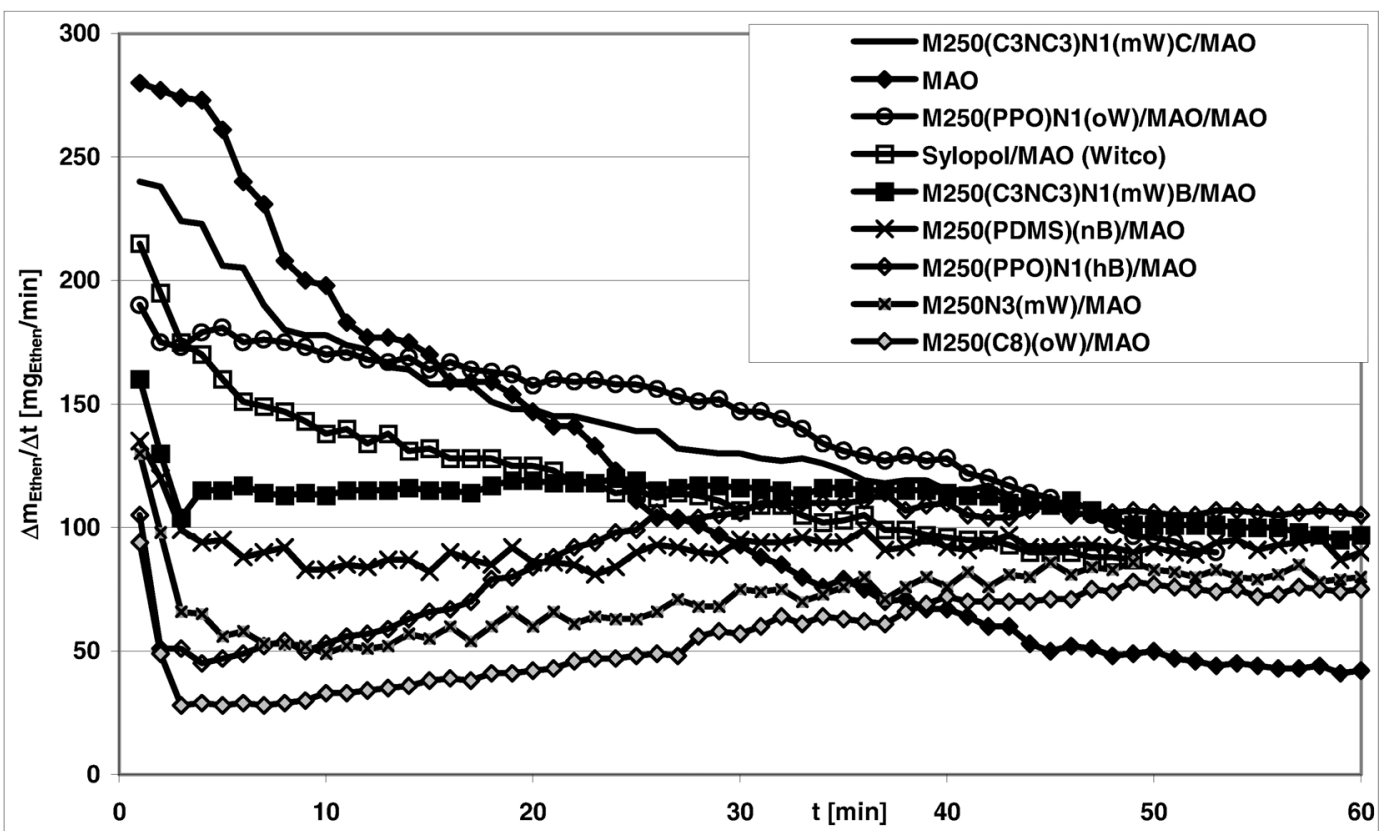

Fig. 5. Activity profiles of M250(C3NC3)N1(mW)C/MAO, MAO, M250(PPO)N1(oW)/MAO/MAO, Sylopol/MAO, M250(C3NC3)N1(mW)B/MAO, M250(PDMS)(nB), M250(PPO)N1(hB)/MAO, M250N3(mW)/MAO and M250(C8) $(\mathrm{oW}) / \mathrm{MAO}$.

different silanol:water ratios, and the two cocatalysts with different silanol:linker:spacer:water ratios, $\mathrm{M} 250(\mathrm{C} 3 \mathrm{NC} 3) \mathrm{N} 1(\mathrm{~mW}) \mathrm{C} / \mathrm{MAO}$ is the most active cocatalyst.

Alterations in the modification process (TEA/MAO in two steps instead of MAO in one step) also lead to changes in activity, as shown by the pair $\mathrm{M} 250(\mathrm{C} 3 \mathrm{NC} 3) \mathrm{N} 1(\mathrm{~mW}) / \mathrm{TEA} / \mathrm{MAO}$ (activity 22.3\%) and $\mathrm{M} 250(\mathrm{C} 3 \mathrm{NC} 3) \mathrm{N} 1(\mathrm{~mW}) \mathrm{A} / \mathrm{MAO}$ (28.3\%), which both have the same support.

Modification of the same support with different methods (MAO or $\mathrm{AlR}_{3} / \mathrm{MAO}$ or MAO/MAO) also influences the resulting polymerization activity. The activity of a two-step aluminiumorganyl-modified cocatalyst $\left(\mathrm{AlR}_{3} / \mathrm{MAO}\right.$ or MAO/MAO) is increased compared to the MAO-modified cocatalyst, if a) the cocatalyst contains a spacer (N1, N2 or N3) and/or the linker C3NC3 and is reacted with TMA/MAO, TEA/MAO or $\mathrm{MAO} / \mathrm{MAO}, \mathrm{b})$ the cocatalyst contains a spacer (N1, $\mathrm{N} 2$ or N3) and the linker PPO, and is reacted with $\mathrm{MAO} / \mathrm{MAO}, \mathrm{c})$ the cocatalyst is obtained by reacting unmodified M250 with MAO/MAO.

\section{Polymerization activity profiles}

During the polymerization process the consumption of ethylene per minute is related to the activity of the catalyst/cocatalyst system, and the plot of consumption of ethylene per minute versus time yields a meaningful polymerization activity profile. For a commercially viable system a profile with a constant ethylene consumption on a high level is required (represented by a horizontal line). An increase of the consumption level results from the generation of new active sites. For heterogeneous polymerization reactions this is attributed to the fragmentation of the solid catalyst particles by polymers growing inside the particle. The surface area is increased drastically and the catalytic centers located on this new surface area become active sites. Fig. 5 shows the activity profiles of the homogeneous and the heterogeneous reference systems (MAO in homogeneous solution and Sylopol/MAO from Witco) as well as the profiles of the two new most active heterogeneous cocatalysts together with some examples of less active cocatalysts.

MAO in homogeneous solution exhibits a strong decrease in its profile, which is due to diffusion control. The profiles of $\mathrm{M} 250(\mathrm{C} 3 \mathrm{NC} 3) \mathrm{N} 1(\mathrm{~mW}) \mathrm{C} / \mathrm{MAO}$, M250(PPO)N1(oW)/MAO/MAO and Sylopol/MAO also show a decrease, but the gradient is much smaller. This is attributed to the fragmentation of the heterogeneous cocatalyst particles which can partially compensate for the diffusion limitation due to the high poly- 
merization activity. M250(C3NC3)N1(mW)B/MAO and M250(PDMS)(nB)/MAO have level profiles for most of the polymerization time, with the slope of $\mathrm{M} 250(\mathrm{C} 3 \mathrm{NC} 3) \mathrm{N} 1(\mathrm{~mW}) \mathrm{B} / \mathrm{MAO}$ decreasing slightly at the end and the activity of M250(PDMS)(nB) increasing somewhat during the second 30 minute period. Again this behaviour is attributed to a combination of diffusion limitation and fragmentation processes. The profiles of all the other cocatalysts exhibit a more or less distinct increase or decrease over time. The strong increase of M250(PPO)N1(hB)/MAO, $\mathrm{M} 250(\mathrm{C} 8)(\mathrm{oW}) / \mathrm{MAO}$ and $\mathrm{M} 250 \mathrm{~N} 3(\mathrm{~mW}) / \mathrm{MAO}$ again is attributed to the fragmentation of the catalyst particles and the concomitant generation of new active sites.

The fragmentation process was obvious from the SEM images of all resulting polymers.

\section{Activity tests with extended polymerization times}

To examine the polymerization profile over a period longer than one hour, the M250(C3NC3)N1 $(\mathrm{mW}) / \mathrm{TEA} / \mathrm{MAO}$ system was chosen, which during $60 \mathrm{~min}$ of polymerization time did not show any diffusion control (no decrease) and exhibited an overall satisfactory performance. Whereas MAO in homogeneous solution clearly showed a strong decrease due to strong diffusion control, M250(C3NC3)N1(mW)/TEA/MAO exhibited a less drastic decrease of ethylene consumption/ polymerization activity starting after the initial 60 min polymerization period.

\section{Variation of the Al:Zr-ratio}

To check whether variations of the Al:Zr-ratio influence the polymerization activity, two cocatalysts $\mathrm{M} 250(\mathrm{C} 3 \mathrm{NC} 3) \mathrm{N} 1(\mathrm{~mW}) \mathrm{B} / \mathrm{MAO}$ and M250(PPO)N1 $(\mathrm{hB}) / \mathrm{MAO})$ as well as MAO were tested together with two different $\mathrm{Al}: \mathrm{Zr}$ ratios (Table 5).

Table 5. Variation of the $\mathrm{Al}: \mathrm{Zr}$ ratio.

\begin{tabular}{lll}
\hline Cocatalysts & $\begin{array}{l}\text { Al:Zr-ratio } \\
{[\text { mol:mol] }}\end{array}$ & $\begin{array}{l}\text { Activity } \\
{[\mathrm{kg} \mathrm{PE} / \mathrm{mol}(\mathrm{Zr})} \\
\text { c(ethylene) h] }\end{array}$ \\
\hline MAO & $2200: 1 / 1100: 1$ & $62200 / 11300$ \\
M250(PPO)N1(hB)/MAO & $2300: 1 / 1400: 1$ & $26800 / 10500$ \\
M250(C3NC3)N1(mW)/MAO & $2300: 1 / 1100: 1$ & $33500 / 8900$ \\
\hline
\end{tabular}

Polymerization conditions: $\mathrm{c}(\mathrm{Zr})=5 \times 10^{-6} \mathrm{~mol} / \mathrm{l} ; \mathrm{Al}_{\text {cocat }}: \mathrm{Zr}=$ $2200: 1-2500: 1 ; \mathrm{Al}_{\text {scav }}: \mathrm{Zr}=1000: 1$; Scavenger: TIBA; $\mathrm{T}=$ $30{ }^{\circ} \mathrm{C} ; \mathrm{p}($ ethylene $)=2$ bar; $\mathrm{c}($ ethylene $)=0.24 \mathrm{~mol} / \mathrm{l} ; \mathrm{t}=1 \mathrm{~h}$.

Upon reduction of the cocatalyst:catalyst ratio from 2200:1 to 1100:1, MAO in solution exhibited a decrease of polymerization activity by $80 \%$, and the two heterogeneous cocatalysts by $73 \%$ for $\mathrm{M} 250(\mathrm{C} 3 \mathrm{NC} 3) \mathrm{N} 1(\mathrm{~mW}) \mathrm{B} / \mathrm{MAO}$ and $61 \%$ for $\mathrm{M} 250$ (PPO)N1(hB)/MAO.

\section{Characterization of polymers by scanning electron mi-} croscopy (SEM)

For the investigation the polymer particles were sputtered with thin layers of gold or palladium/platinum. The imaging process and the principle of SEM is described elsewhere [32].

The polymers have an amorphous structure with the remaining silica particles/agglomerates embedded into the polymer matrix. The silica contents of the polymer, and the size of the silica agglomerates (number of silica spheres in one agglomerate) are closely related to the polymerization activity of the cocatalyst. Whereas it was almost impossible to find silica spheres in the polymer produced using $\mathrm{M} 250(\mathrm{C} 3 \mathrm{NC} 3) \mathrm{N} 1(\mathrm{~mW}) \mathrm{C} / \mathrm{MAO}$, the polymer obtained with M250(PDMS)(nB)/MAO showed up to 50 mostly separate silica spheres in a given spot on the surface. The surface of polymers obtained using the poorly active cocatalysts $\mathrm{M} 250(\mathrm{C} 8) \mathrm{N} 1(\mathrm{oW}) / \mathrm{MAO}$ or $\mathrm{M} 250(\mathrm{PPO})(\mathrm{mW}) / \mathrm{MAO}$ were completely covered with silica spheres and their agglomerates and can better be described as composites consisting of silica and polyethylene (Fig. 6).

These morphologies definitely prove our concept to prepare fragmentable cocatalyst particles via surface modification using organoalkoxysilanes.

\section{Conclusion}

Highly active heterogeneous cocatalysts for the polymerization of ethylene have been prepared using supports consisting of interlinked and surface-modified spherical silica particles obtained with aminoorgano-trialkoxysilanes as spacers and bis(alkoxysilyl)organyls as linkers. Treatment of these supports with MAO in a one step-reaction or with TMA/MAO, TEA/MAO, or MAO/MAO in two step-reactions afforded cocatalysts comparable in polymerization activity to MAO in homogeneous solution, and exceeding the reactivity of the commercially available heterogeneous reference system Sylopol/MAO from Witco by $45 \%$. The new cocatalysts show fragmentation of the catalyst particles during polymerization. The fragmentation of the supports has been proven by using SEM and EDX and is obvious from the polymerization activity profiles. Leaching of MAO from the heterogeneous cocatalysts 


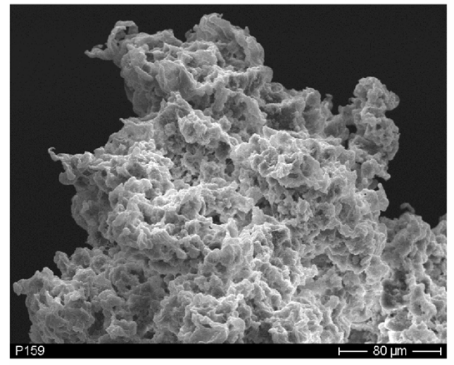

a)

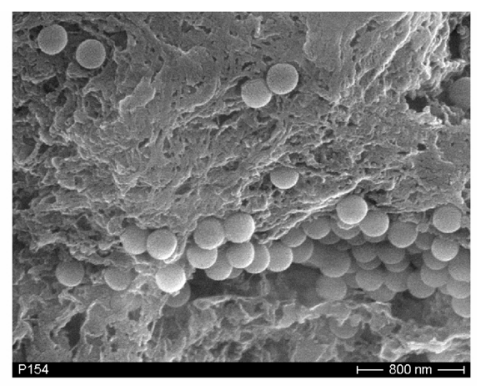

b)

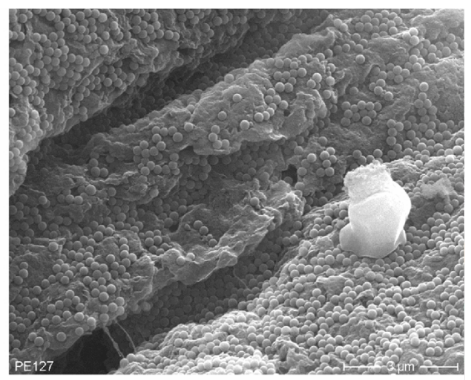

c)

Fig. 6. SEM images of PE made with a) M250(C3NC3)N1(mW)A/MAO $(350 \times)$, b) M250(PDMS)(nB) $(35000 \times)$ and c) $\mathrm{M} 250(\mathrm{C} 8) \mathrm{N} 1(\mathrm{oW}) / \mathrm{MAO}(15000 \times$ magnification $)$.

containing spacers and linkers over standard periods of time was shown to be less than $10 \%$ of the total Al-content, whereas that of cocatalysts containing unmodified silica was $22 \%$.

\section{Experimental Section}

All reactions and work-up procedures including filtration and centrifugation were performed using Schlenk techniques with nitrogen as inert gas. For filtration a commercially available glass filter for use with Teflon filter membranes (200 $\mathrm{nm}$ pore size) was remodeled to be used under inert atmosphere for filtration of Monospher 250 suspensions. The solvents were dried under inert atmosphere using sodium metal with benzophenone as indicator. The solvents were refluxed until the colour changed to purple and then distilled freshly prior to use. Trimethylaluminium (TMA), triethylaluminium (TEA), di-iso-butylaluminium hydride (DIBAH) and methylaluminoxane (MAO, $10 \mathrm{wt} . \%$ solution in toluene) were used as received from Witco. Transfer of the aluminiumalkyls and the solvents was performed using dried syringes with metal needles. The glass ware was evacuated, heated to $100{ }^{\circ} \mathrm{C}$, cooled and flushed with nitrogen. Monospher 250 (M250) was donated by Merck, Darmstadt. The properties of the silica gel and the drying conditions employed are listed in the Tables 6 and 7. The silanol number for M250 was calculated to $6-7 \mathrm{OH} / \mathrm{nm}^{2}$ and $0,12 \mathrm{mmol} \mathrm{OH} / \mathrm{g}$. Elemental analyses were performed using a Perkin-Elmer CHNS/O-analyzer 2400, series II. For SEM and EDX a Hitachi S-4000 Field emission scanning electron microscope (FESEM) was used with 7-20 keV energies, with the samples sputtered with a $2-4 \mathrm{~nm}$ thick gold or Pt/Pd-layer.

Table 6. Properties of the employed silica.

\begin{tabular}{lccccc}
\hline Silica & $\begin{array}{c}\text { Average } \\
\text { particle } \\
\text { size }[\mathrm{nm}]\end{array}$ & $\begin{array}{c}\text { Particle size } \\
\text { distribution } \\
{[\mathrm{nm}]}\end{array}$ & $\begin{array}{c}\text { Specific } \\
\text { surface } \\
{\left[\mathrm{m}^{2} / \mathrm{g}\right]}\end{array}$ & $\begin{array}{c}\text { Pore } \\
\text { volume } \\
{[\mathrm{ml} / \mathrm{g}]}\end{array}$ & $\begin{array}{c}\text { Pore } \\
\text { diameter } \\
{[\mathrm{nm}]}\end{array}$ \\
\hline $\mathrm{M} 250$ & 235 & $225-245$ & 12 & 0 & 0 \\
\hline
\end{tabular}

Table 7. Drying conditions for the employed silicas.

\begin{tabular}{lclc}
\hline Silica & Lot No. & Drying conditions & Water content [wt. \%] \\
\hline M250 & 1 & $150^{\circ} \mathrm{C} / 6 \mathrm{~h} /<0.01 \mathrm{mbar}$ & 0.8 \\
M250 & 2 & $150^{\circ} \mathrm{C} / 8 \mathrm{~h} /<0.01 \mathrm{mbar}$ & 0.335 \\
M250 & 3 & $150^{\circ} \mathrm{C} / 6 \mathrm{~h} /<0.01 \mathrm{mbar}$ & 1.6 \\
M250 & 4 & $165^{\circ} \mathrm{C} / 6 \mathrm{~h} /<0.01 \mathrm{mbar}$ & 0.87 \\
\hline
\end{tabular}

General preparative procedures

1) One-step heterogenization of MAO or aluminiumorganyls on modified M250

5 to $30 \mathrm{~g}$ of a modified support are suspended in 50 to $150 \mathrm{ml}$ of toluene with stirring and applying ultrasound for 10 minutes. The desired amount of a 10 wt.\% solution of MAO or aluminiumorganyl in toluene is added within 5 to 20 minutes (depending on the amount of solution). The suspension is heated to reflux for 8 to $20 \mathrm{~h}$ and filtered using a Teflon membrane (pore size $200 \mathrm{~nm}$ ). The residue is washed with $2-5$ portions of toluene and $1-3$ portions of hexane or pentane. The solid is dried in vacuo to reach a pressure of 0.03 mbar or below. The dry solids are usually colourless, easy to hard grindable. In air it is weakly (faint smell after burned plastic) to very reactive (smoke, turns brown, strong smell after burned plastic). Upon addition of water evolution of gas and occasionally small flames are observed.

2) Two-step heterogenization of aluminiumtriorganyl and MAO on modified M250: M250.../TMA/MAO, M250.../TEA/MAO and M250.../MAO/MAO

The two reaction steps are performed sequentially using procedure 1. The properties of the products are similar to those obtained in the one-step process (above). All modified silicas including their nomenclature, the employed equivalent ratios of silanol:linker:spacer:water, the mass increase ("yield") and the characterization methods used are listed in the preceding paper [1]. Table 8 presents all heterogenized aluminiumorganyls and cocatalysts based on M250 including their nomenclature, the amounts and type of starting material, 
Table 8. Preparation of heterogenized aluminiumorganyls and cocatalysts based on M250.

\begin{tabular}{|c|c|c|c|c|c|c|c|c|c|}
\hline Cocatalyst & Based on support & $\begin{array}{l}\text { Modified } \\
\text { silica [g] }\end{array}$ & $\begin{array}{l}\text { Al-organyl } \\
{[\mathrm{ml}]} \\
([\mathrm{mmol}])^{\mathrm{a}}\end{array}$ & $\begin{array}{l}\text { Solvent } \\
{[\mathrm{ml}]^{\mathrm{b}}}\end{array}$ & $\begin{array}{l}\text { RT [h], } \\
\text { T } \\
{\left[{ }^{\circ} \mathrm{C}\right]^{b}}\end{array}$ & $\begin{array}{l}\text { Solvent for } \\
\text { washing } \\
{[\mathrm{ml}]^{\mathrm{b}}}\end{array}$ & $\begin{array}{l}\text { Yield } \\
{[\mathrm{g}]}\end{array}$ & $\begin{array}{l}\mathrm{IMaR}^{\mathrm{b}} \\
{[\mathrm{g}]} \\
([\%])\end{array}$ & $\begin{array}{l}\text { Al-cont. }{ }^{\mathrm{c}} \\
{[\mathrm{mmolAl} / \mathrm{g}]}\end{array}$ \\
\hline$\overline{\mathrm{M} 250 / \mathrm{MAO}}$ & M250 & 23.13 & $50(78.5)$ & $70 \mathrm{t}$ & $\begin{array}{l}12 \mathrm{r}, \\
24 \mathrm{rt}\end{array}$ & $\begin{array}{l}2 \times 50,40, \\
30 \mathrm{hx}\end{array}$ & 23.59 & $\begin{array}{l}+0.46 \\
(+2)\end{array}$ & 0.74 \\
\hline M250/MAO/MAO & M250/MAO & 11.38 & $70(110)$ & $50 \mathrm{hp}$ & $12 \mathrm{r}$ & $\begin{array}{l}40 \mathrm{hx}, 2 \times 25 \mathrm{t} \\
3 \times 30 \mathrm{hx}\end{array}$ & 12.9 & $\begin{array}{l}+1.5 \\
(+13.4)\end{array}$ & 2.75 \\
\hline $\mathrm{M} 250 \mathrm{~N} 1(\mathrm{~mW}) / \mathrm{MAO}$ & $\mathrm{M} 250 \mathrm{~N} 1(\mathrm{~mW})$ & 17.04 & $100(157)$ & $80 \mathrm{hp}$ & $12 \mathrm{r}$ & $\begin{array}{l}3 \times 30 \mathrm{t} \\
3 \times 30 \mathrm{hx}\end{array}$ & 22.12 & $\begin{array}{l}+2.52 \\
(+12.9)\end{array}$ & 2.6 \\
\hline M250N3(oW)/TMA/MAO & M250N3(oW)/TMA & 6.47 & $80(125.6)$ & $80 \mathrm{t}$ & $12 \mathrm{r}$ & $\begin{array}{l}50,40,35 \mathrm{t}, \\
50,40,35 \mathrm{hx}\end{array}$ & 8.83 & $\begin{array}{l}+2.4 \\
(+36.5)\end{array}$ & 5.9 \\
\hline $\mathrm{M} 250 \mathrm{~N} 3(\mathrm{~mW}) / \mathrm{MAO}$ & $\mathrm{M} 250 \mathrm{~N} 3(\mathrm{~mW})$ & 17.66 & 95 (149) & - & $14 \mathrm{r}$ & $\begin{array}{l}50,30, \\
2 \times 30 \mathrm{hx}, 30 \mathrm{p}\end{array}$ & 23.68 & $\begin{array}{l}+6.02 \\
(+34.1)\end{array}$ & 3.79 \\
\hline M250(C8)(oW)/MAO & M250(C8)(oW) & 21.37 & $67(105.2)$ & $100 \mathrm{t}$ & $12 \mathrm{r}$ & $\begin{array}{l}30,50 \mathrm{t} \\
2 \times 40,30 \mathrm{hx}\end{array}$ & 22.16 & $\begin{array}{l}+0.79 \\
(+3.7)\end{array}$ & 1.15 \\
\hline $\mathrm{M} 250(\mathrm{C} 8)(\mathrm{mW}) / \mathrm{MAO}$ & $\mathrm{M} 250(\mathrm{C} 8)(\mathrm{mW})$ & 16.38 & $80(125.6)$ & $80 \mathrm{t}$ & $12 \mathrm{r}$ & $\begin{array}{l}4 \times 40 \mathrm{t} \\
2 \times 40 \mathrm{hx}\end{array}$ & 17.69 & $\begin{array}{l}+1.31 \\
(+8)\end{array}$ & 1.79 \\
\hline M250(C8)N1(oW)/MAO & $\mathrm{M} 250(\mathrm{C} 8) \mathrm{N} 1(\mathrm{oW})$ & 23.74 & $70(110)$ & $90 \mathrm{t}$ & $12 \mathrm{r}$ & $\begin{array}{l}3 \times 35 \mathrm{t} \\
3 \times 35 \mathrm{hx}\end{array}$ & 24.95 & $\begin{array}{l}+1.21 \\
(+5.1)\end{array}$ & 1.4 \\
\hline $\mathrm{M} 250(\mathrm{C} 8) \mathrm{N} 1(\mathrm{hB}) / \mathrm{MAO}$ & $\mathrm{M} 250(\mathrm{C} 8) \mathrm{N} 1(\mathrm{hB})$ & 21.13 & $65(102.1)$ & $100 \mathrm{t}$ & $12 \mathrm{r}$ & $\begin{array}{l}2 \times 40 \mathrm{t}, 45 \\
40,35 \mathrm{hx}\end{array}$ & 21.36 & $\begin{array}{l}+0.26 \\
(+1.2)\end{array}$ & 0.883 \\
\hline $\mathrm{M} 250(\mathrm{PPO})(\mathrm{oW}) / \mathrm{MAO}$ & M250(PPO)(oW) & 21.67 & $125(169.25)$ & $50 \mathrm{t}$ & $\begin{array}{l}12 \mathrm{r}, \\
72 \mathrm{rt}\end{array}$ & $2 \times 40,2 \times 50 t$ & 25.99 & $\begin{array}{l}+4.32 \\
(+20)\end{array}$ & 2.93 \\
\hline $\mathrm{M} 250(\mathrm{PPO})(\mathrm{mW}) / \mathrm{MAO}$ & $\mathrm{M} 250(\mathrm{PPO})(\mathrm{mW})$ & 11.72 & $60(94.2)$ & $100 \mathrm{t}$ & $12 \mathrm{r}$ & $\begin{array}{l}50,6 \times 40 \mathrm{t} \\
2 \times 30 \mathrm{hx}\end{array}$ & 14.34 & $\begin{array}{l}+2.62 \\
(+22.3)\end{array}$ & 3.61 \\
\hline M250(PPO)N1(oW)/MAO & M250(PPO)N1(oW) & 18.24 & $120(188.4)$ & $100 \mathrm{t}$ & $20 \mathrm{r}$ & $\begin{array}{l}2 \times 40 \mathrm{t} \\
2 \times 50 \mathrm{hx}\end{array}$ & 22.25 & $\begin{array}{l}+4.01 \\
(+22)\end{array}$ & 3.32 \\
\hline M250(PPO)N1(oW)/MAO/MAO & $\mathrm{M} 250(\mathrm{PPO}) \mathrm{N} 1(\mathrm{oW}) / \mathrm{MAO}$ & 10.54 & $50(78.5)$ & $100 \mathrm{t}$ & $48 \mathrm{r}$ & $\begin{array}{l}40,50 \\
2 \times 45 \mathrm{t}, 15 \\
30,50 \mathrm{hp}\end{array}$ & 12.62 & $\begin{array}{l}+2.08 \\
(+19.7)\end{array}$ & 5.7 \\
\hline M250(PPO)N1(hB)/MAO & $\mathrm{M} 250(\mathrm{PPO}) \mathrm{N} 1(\mathrm{hB})$ & 9.61 & $60(94.2)$ & $80 \mathrm{t}$ & $\begin{array}{l}18 \mathrm{r} \\
24 \mathrm{rt}\end{array}$ & $\begin{array}{l}5 \times 40 \mathrm{t} \\
45 \mathrm{hx}\end{array}$ & 11.42 & $\begin{array}{l}+1.81 \\
(+18.8)\end{array}$ & 2.68 \\
\hline M250(PPO)N1(hB)/TEA/MAO & $\mathrm{M} 250(\mathrm{PPO}) \mathrm{N} 1(\mathrm{hB}) / \mathrm{TEA}$ & 4.97 & $25(39.25)$ & $80 \mathrm{t}$ & $12 \mathrm{r}$ & $\begin{array}{l}4 \times 40 \mathrm{t} \\
40 \mathrm{hx}\end{array}$ & 5.3 & $\begin{array}{l}+0.33 \\
(+6.6)\end{array}$ & 2.39 \\
\hline M250(PPO)N1(mW)/MAO & $\mathrm{M} 250(\mathrm{PPO}) \mathrm{N} 1(\mathrm{~mW})$ & 11.68 & $60(94.2)$ & $80 \mathrm{t}$ & $42 \mathrm{r}$ & $5 \times 40 \mathrm{t}$ & 13.7 & $\begin{array}{l}+2.14 \\
(+18.3)\end{array}$ & 3.12 \\
\hline M250(PDMS)(nB)/MAO & M250(PDMS)(nB) & 9.67 & $70(109.9)$ & $80 \mathrm{t}$ & $18 \mathrm{r}$ & $\begin{array}{l}3 \times 35 \mathrm{xt} \\
2 \times 40 \mathrm{hx}\end{array}$ & 11.03 & $\begin{array}{l}+1.36 \\
(+14.1)\end{array}$ & 2.66 \\
\hline M250(PDMS)(oW)/MAO & M250(PDMS)(oW) & 10.13 & $50(78.5)$ & $100 \mathrm{t}$ & $65 \mathrm{r}$ & $\begin{array}{l}4 \times 40 \mathrm{t} \\
2 \times 50 \mathrm{hx}\end{array}$ & 11.77 & $\begin{array}{l}+1.64 \\
(+16.2)\end{array}$ & 3.0 \\
\hline M250(PDMS)N1(nB)/MAO & M250(PDMS)N1(nB) & 12.09 & $100(157)$ & $80 \mathrm{t}$ & $18 \mathrm{r}$ & $\begin{array}{l}3 \times 40 \mathrm{t}, \\
2 \times 40 \mathrm{hx}\end{array}$ & 17.14 & $\begin{array}{l}+5.05 \\
(+41.8)\end{array}$ & 2.2 \\
\hline M250(C3NC3)(oW)/MAO & $\mathrm{M} 250(\mathrm{C} 3 \mathrm{NC} 3)(\mathrm{oW})$ & 13.99 & $95(149.2)$ & $80 \mathrm{t}$ & $12 \mathrm{r}$ & $\begin{array}{l}60 \mathrm{t}, 50 \\
70 \mathrm{hx}\end{array}$ & 14.89 & $\begin{array}{l}+0.9 \\
(+6.4)\end{array}$ & 1.55 \\
\hline $\mathrm{M} 250(\mathrm{C} 3 \mathrm{NC} 3)(\mathrm{mW}) / \mathrm{MAO}$ & $\mathrm{M} 250(\mathrm{C} 3 \mathrm{NC} 3)(\mathrm{mW})$ & 11.9 & $50(78.5)$ & $100 \mathrm{t}$ & $12 \mathrm{r}$ & $\begin{array}{l}4 \times 40 \mathrm{t} \\
40 \mathrm{hx}\end{array}$ & 11.98 & $\begin{array}{l}+0.08 \\
(+0.6)\end{array}$ & 1.07 \\
\hline $\mathrm{M} 250(\mathrm{C} 3 \mathrm{NC} 3) \mathrm{N} 1(\mathrm{oW}) / \mathrm{MAO}$ & $\mathrm{M} 250(\mathrm{C} 3 \mathrm{NC} 3) \mathrm{N} 1(\mathrm{oW})$ & 17.04 & $95(149.2)$ & $90 \mathrm{t}$ & $12 \mathrm{r}$ & $\begin{array}{l}35,20,30 \\
45 \mathrm{t}, 2 \times 30 \mathrm{hx}\end{array}$ & 19.66 & $\begin{array}{l}+2.62 \\
(+15.4)\end{array}$ & 2.64 \\
\hline $\mathrm{M} 250(\mathrm{C} 3 \mathrm{NC} 3) \mathrm{N} 1(\mathrm{hB}) / \mathrm{MAO}$ & $\mathrm{M} 250(\mathrm{C} 3 \mathrm{NC} 3) \mathrm{N} 1(\mathrm{hB})$ & 18.62 & $110(172.7)$ & $80 \mathrm{t}$ & $17 \mathrm{r}$ & $\begin{array}{l}50,4 \times 40 \mathrm{t} \\
2 \times 50 \mathrm{hx}\end{array}$ & 21.19 & $\begin{array}{l}+2.57 \\
(+13.8)\end{array}$ & 2.53 \\
\hline $\mathrm{M} 250(\mathrm{C} 3 \mathrm{NC} 3) \mathrm{N} 1(\mathrm{~mW}) \mathrm{A} / \mathrm{MAO}$ & $\mathrm{M} 250(\mathrm{C} 3 \mathrm{NC} 3) \mathrm{N} 1(\mathrm{MW}) \mathrm{A}$ & 11.02 & $50(78.5)$ & $100 \mathrm{t}$ & $\begin{array}{l}18 \mathrm{r}, \\
24 \mathrm{rt}\end{array}$ & $\begin{array}{l}4 \times 30 t \\
2 \times 40 \mathrm{hx}\end{array}$ & 14.38 & $\begin{array}{l}+3.36 \\
(+30.5)\end{array}$ & 4.21 \\
\hline $\mathrm{M} 250(\mathrm{C} 3 \mathrm{NC} 3) \mathrm{N} 1(\mathrm{~mW}) \mathrm{A} / \mathrm{TEA} / \mathrm{MAO}$ & $\mathrm{M} 250(\mathrm{C} 3 \mathrm{NC} 3) \mathrm{N} 1(\mathrm{~mW}) \mathrm{A} / \mathrm{TEA}$ & 16.89 & $130(204.1)$ & $80 \mathrm{t}$ & $18 \mathrm{r}$ & $\begin{array}{l}50,5 \times 40 \mathrm{t} \\
2 \times 35 \mathrm{hx}\end{array}$ & 20.8 & $\begin{array}{l}+3.91 \\
(+23.1)\end{array}$ & 4.27 \\
\hline $\mathrm{M} 250(\mathrm{C} 3 \mathrm{NC} 3) \mathrm{N} 1(\mathrm{~mW}) \mathrm{B} / \mathrm{MAO}$ & $\mathrm{M} 250(\mathrm{C} 3 \mathrm{NC} 3) \mathrm{N} 1(\mathrm{~mW}) \mathrm{B}$ & 18.4 & $100(157)$ & $100 \mathrm{t}$ & $20 \mathrm{r}$ & $\begin{array}{l}4 \times 40 \mathrm{t} \\
40 \mathrm{hx}\end{array}$ & 23.16 & $\begin{array}{l}+4.76 \\
(+25.9)\end{array}$ & 2.76 \\
\hline $\mathrm{M} 250(\mathrm{C} 3 \mathrm{NC} 3) \mathrm{N} 3(\mathrm{~mW}) / \mathrm{TEA}$ & $\mathrm{M} 250(\mathrm{C} 3 \mathrm{NC} 3) \mathrm{N} 3(\mathrm{~mW})$ & 28.15 & $25(182.8)$ & $130 \mathrm{t}$ & $64 \mathrm{r}$ & $\begin{array}{l}70,40 \\
35 \mathrm{hx}\end{array}$ & 29.92 & $\begin{array}{l}+1.77 \\
(+6.3)\end{array}$ & 1.61 \\
\hline $\mathrm{M} 250(\mathrm{C} 3 \mathrm{NC} 3) \mathrm{N} 3(\mathrm{~mW}) / \mathrm{TEA} / \mathrm{MAO}$ & $\mathrm{M} 250(\mathrm{C} 3 \mathrm{NC} 3) \mathrm{N} 3(\mathrm{~mW}) / \mathrm{TEA}$ & 21.55 & $200(314)$ & - & $60 \mathrm{r}$ & $\begin{array}{l}5 \times 50 \mathrm{t} \\
2 \times 50 \mathrm{hx}\end{array}$ & 28.29 & $\begin{array}{l}+6.74 \\
(+31.3)\end{array}$ & 5.52 \\
\hline $\mathrm{M} 250(\mathrm{C} 3 \mathrm{NC} 3) \mathrm{N} 3(\mathrm{~mW}) / \mathrm{MAO}$ & $\mathrm{M} 250(\mathrm{C} 3 \mathrm{NC} 3) \mathrm{N} 3(\mathrm{~mW})$ & 18.74 & $100(157)$ & $130 \mathrm{t}$ & $64 \mathrm{r}$ & $\begin{array}{l}50,3 \times 40 \\
30 \mathrm{t}, 40,30 \mathrm{hx}\end{array}$ & 24.59 & $\begin{array}{l}+5.85 \\
(+31.2)\end{array}$ & 4.2 \\
\hline $\mathrm{M} 250(\mathrm{C} 3 \mathrm{NC} 3) \mathrm{N} 3(\mathrm{~mW}) / \mathrm{MAO} / \mathrm{MAO}$ & $\mathrm{M} 250(\mathrm{C} 3 \mathrm{NC} 3) \mathrm{N} 3(\mathrm{~mW}) / \mathrm{MAO}$ & 10.50 & $50(78.5)$ & $50 \mathrm{t}$ & $\begin{array}{l}20 \mathrm{r} \\
24 \mathrm{rt}\end{array}$ & $\begin{array}{l}2 \times 50,2 \times 40 \mathrm{t} \\
2 \times 50 \mathrm{hx}\end{array}$ & 12.22 & $\begin{array}{l}+1.72 \\
(+16.4)\end{array}$ & 6.07 \\
\hline
\end{tabular}

${ }^{\mathrm{a}} \mathrm{MAO}$ was used as $10 \mathrm{wt} . \%$ solution in toluene; ${ }^{\mathrm{b}}$ abbreviations: $\mathrm{RT}=$ reaction time; $\mathrm{T}=$ temperature $; \mathrm{IMaR}=$ increase of mass after reaction; $\mathrm{t}=\mathrm{toluene} ; \mathrm{hp}=$ heptane; hx = hexane; $\mathrm{p}=$ pentane; $-=$ not performed $/$ not used; $\mathrm{r}=$ reflux; $\mathrm{rt}=$ room temperature ${ }^{\mathrm{c}} \mathrm{Al}$-content determined by AAS 
the solvent, the increase of mass after the reaction (IMaR), and the reaction time.

\section{Leaching tests}

First, M250/MAO/MAO was tested twice: $1 \mathrm{~g}$ of M250/ MAO/MAO was stirred in $200 \mathrm{ml}$ of toluene at $35{ }^{\circ} \mathrm{C}$ for $2 \mathrm{~h}$ (polymerization conditions) and then filtered and washed. The Al-content decreased by $22 \%$ ( $-0.6 \mathrm{mmol}$ $\mathrm{Al} / \mathrm{g}$ ). In a second experiment, $9.21 \mathrm{~g}$ of M250/MAO/MAO was stirred at $70{ }^{\circ} \mathrm{C}$ for $3 \mathrm{~h}$ in $200 \mathrm{ml}$ of toluene. The suspension was filtered and washed with $30 \mathrm{ml}$ of hot hexane. The Al-content decreased by $10 \%$. In a polymerization experiment using this material, the polymerization activity decreased by $50 \%$, proving that MAO supported on unmodified silica is active as a cocatalyst mainly due to leached MAO acting as a homogeneous cocatalyst. In another test $4.33 \mathrm{~g}$ of $\mathrm{M} 250 \mathrm{~N} 3(\mathrm{oW}) / \mathrm{TMA} / \mathrm{MAO}$ was stirred in $200 \mathrm{ml}$ of toluene at $55{ }^{\circ} \mathrm{C}$ for $4.5 \mathrm{~h}$. The suspension was filtered hot and washed twice with $40 \mathrm{ml}$ of hot hexane. The Al-content decreased by $3.5 \%$, the polymerization activity by $7 \%$. M250(C3NC3)N1(mW)/TEA/MAO was filtered hot and washed extensively with hot toluene $(5 \times 50 \mathrm{ml})$ and hexane $(2 \times 50 \mathrm{ml})$. Compared with $\mathrm{M} 250(\mathrm{C} 3 \mathrm{NC} 3) \mathrm{N} 3(\mathrm{~mW}) / \mathrm{MAO} / \mathrm{MAO}$, the Al-content was lowered by $9 \%$.

\section{Polymerizations}

$\mathrm{Cp}_{2} \mathrm{ZrCl}_{2}$ was heterogenized in situ by stirring it together with the cocatalyst in approx. $10 \mathrm{ml}$ of toluene for $10 \mathrm{~min}$. The slurry was then injected into a 11 autoclave, filled with $200 \mathrm{ml}$ of toluene and $1 \mathrm{ml}$ of DIBAH. Polymerization was performed at $30{ }^{\circ} \mathrm{C}$ with an ethylene pressure of 2 bar. After $1 \mathrm{~h}$ the polymer suspension was quenched using $\mathrm{EtOH}$ and $\mathrm{HCl}$, filtered, the polymer washed with $\mathrm{EtOH}$ and diluted aqueous $\mathrm{HCl}$, and dried. The polymerization activity was calculated from the yield of polymer, subtracting $85 \%$ of the mass of silica (added together with the heterogeneous cocatalyst for polymerization). The difference of $15 \%$ results from loss of silica during the filtration process using paper filters. The results of the best cocatalysts are listed in Table 4 .

\section{Acknowledgements}

This work was supported by the Fonds der Chemischen Industrie, the Bundesministerium für Bildung und Forschung (BMBF 03C0295A+B), the Deutsche Forschungsgemeinschaft (Graduiertenkolleg "Synthetische, mechanistische und reaktionstechnische Aspekte von Metallkatalysatoren") and the Merck KgaA. We thank Dipl.-Ing. U. Gernert (TU Berlin) for the SEM examinations, Dr. T. Eberle and Dr. K. Köhler (Merck, Darmstadt) for helpful discussions. Monospher 250 was kindly donated by Merck, Darmstadt.

[8] W.P. Long, D. S. Breslow, Liebigs Ann. Chem. 463 (1975).

[9] a) W. Kaminsky, J. Kopf, H. Sinn, H. J. Vollmer, Angew. Chem. 88, 688 (1976); Angew. Chem. Int. Ed. Engl. 15, 629 (1976); b) A. Andresen, H. G. Cordes, J. Herwig, W. Kaminsky, A. Merck, R. Mottweiler, J. Pein, H. Sinn, H. J. Vollmer, Angew. Chem. 88, 689 (1976); Angew. Chem. Int. Ed. Engl. 15, 630 (1976); c) W. Kaminsky, in R. B. Seymour, T. Cheng (eds): History of Polyolefins, p. 257, Reidel Publ., Dordrecht (1986); d) H. Sinn, W. Kaminsky, H. J. Vollmer, R. Woldt, Angew. Chem. 92, 396 (1980); Angew. Chem. Int. Ed. Engl. 19, 390 (1980); e) W. Kaminsky, Macromol. Chem. Phys. 197, 3907 (1996).

[10] a) J.J. Eisch, S.I. Bombrick, G.X. Zheng, Organometallics 12, 3856 (1993); b) P.J. T. Tait, R. Ediati, in W. Kaminsky (ed.): Metalorganic Catalysts for Synthesis and Polymerization, p. 307, Springer, Berlin (1999); c) R. F. Jordan, W.E. Dasher, S.F. Echols, J. Am. Chem. Soc. 108, 1718 (1986); d) J. Bliemeister, W. Hagendorf, A. Harder, B. Heitmann, I. Schimmel, E. Schmedt, W. Schnuchel, H. Sinn, L. Tikwe, N. von Thienen, K. Urlass, H. Winter, O. Zarncke, in G. Fink, R. Mühlhaupt, H. H. Brintzinger (eds): Ziegler Catalysts, p. 57, Springer, Berlin (1995). 
[11] J. L. Eilertsen, E. Rytter, M. Ystenes, in W. Kaminsky (ed.): Metalorganic Catalysts for Synthesis and Polymerization, p. 136, Springer, Berlin (1999).

[12] a) K. Kallio, J. Kauhanen, in R. Blom, A. Follestad, E. Rytter, M. Tilset, M. Ystenes (eds): Organometallic Catalysts and Olefin Polymerization; Catalysts for a New Millenium, p. 14, Springer, Berlin (2001); b) R. Leino, H. Luttikhedde, Macromolecules 30, 3477 (1997).

[13] a) H. Sinn, J. Bliemeister, D. Clausnitzer, L. Tikwe, H. Winter, O. Zarncke, in W. Kaminsky, H. Sinn (eds): Transition Metals and Organometallics as Catalysts for Olefin Polymerization, p. 257, Springer, Berlin (1987); b) H. Sinn, Macromol. Symp. 97, 27 (1995); c) Y. Koide, S. G. Bott, A. R. Barron, Organometallics 12, 2213 (1993); d) H. Sinn, I. Schimmel, M. Ott, N. von Thienen, A. Harder, W. Hagendorf, B. Heitmann, E. Haupt, in W. Kaminsky (ed.): Metalorganic Catalysts for Synthesis and Polymerization, p. 105, Springer, Berlin (1999); e) D. W. Imhoff, C. S. Simeral, S. S. Sangokoya, J. H. Peel, Organometallics 19, 1941 (1998).

[14] A. Echte, Handbuch der Technischen Polymerchemie, VCH, Weinheim (1993).

[15] a) W. Kaminsky, C. Strübel, J. Mol. Cat. A: Chem. 128, 191 (1998); b) W. Spaleck, A. Winter, B. Bachmann, V. Dolle, F. Kuber, J. Rohrmann, Abstracts of the MetCon '93, Houston 189 (1993).

[16] C.-H. Lin, C.-Y. Sheu, Macromol. Rapid Commun. 21, 1058 (2000).

[17] R. J. Wijngaarden, A. Kronberg, K. R. Westerterp, Industrial Catalysis, VCH Wiley, Weinheim (1998).

[18] a) G. G. Hlatky, Chem. Rev. 100, 1347 (2000); b) E. Y.X. Chen, T. J. Marks, Chem. Rev. 100, 1391 (2000).

[19] a) J.F. Le Page, Applied Heterogeneous Catalysis Design, Manufacture, Use of Solid Catalysts, Editions Technip. Paris (1987); b) E. Gallei, E. Schwab, Catal. Today 51, 535 (1999); c) Y. Iwasawa, in Y. Iwasawa (ed.): Tailored Metal Catalysts, p. 1, Reidel, Dordrecht (1986).

[20] A. Choplin, F. Quignard, Coord. Chem. Rev. 178, 1679 (1998).
[21] a) M. Capka, Collect. Czech. Chem. Commun. 55, 2801 (1990); b) L.L. Murell, in J. J. Burton, R. L. Garten (eds): Advanced Materials in Catalysis, p. 236, Academic Press, New York (1977).

[22] D. Arrowsmith, W. Kaminsky, A.-M. Schauwienold, U. Weingarten, J. Mol. Catal. A: Chem. 160, 97 (2000).

[23] T. Tsutsui, N. Kashiwa, Polymer 32, 2671 (1991).

[24] J. Jin, T. Uozumi, K. Soga, Macromol. Chem. Phys. 197, 849 (1996).

[25] C. Janiak, B. Rieger, R. Voelkel, H.-G. Braun, J. Polym. Chem., Polym. Sci. 31, 2959 (1993).

[26] D. Lee, S. Shin, D. Lee, Macromol. Symp. 97, 195 (1995).

[27] C. Bergemann, G. Luft, Chem. Eng. Technol. 21, 33 (1998).

[28] A. Köppl, H. G. Alt, J. Mol. Catal. A: Chem. 165, 23 (2001).

[29] A. Köppl, H. G. Alt, R. Schmidt, J. Organomet. Chem. 577, 351 (1999).

[30] E. F. Vansant, P. Van Der Voort, K. C. Vrancken, Characterization and Chemical Modification of the Silica Surface (Studies in Surface Science and Catalysis Vol. 93), Elsevier, Amsterdam (1995).

[31] a) R. Widmaier, PhD Thesis, Technische Universität Berlin (2001); b) T. Eberle, K. Köhler, H. Schumann, B.C. Wassermann, K. Lange, R. Widmaier, Merck Patent $\mathrm{GmbH}$, Darmstadt, Deutsche Offenlegungsschrift DE 10151914 (2001/2003); WO 03/035252 (2002/2003); c) K. Köhler, E. Poetsch, H. Schumann, B. C. Wassermann, K. Lange, R. Widmaier, Merck Patent $\mathrm{GmbH}$, Darmstadt, Deutsche Offenlegungsschrift DE 10163457 (2001/2003); WO 03/053578 (2002/2003).

[32] a) G. Bergeret, P. Gallezot, in G. Ertl, H. Knözinger, J. Weitkamp (eds): Handbook of Heterogeneous Catalysis, Vol. 1, p. 453, VCH, Weinheim (1997); b) A. K. Datye, in G. Ertl, H. Knözinger, J. Weitkamp (eds): Handbook of Heterogeneous Catalysis, Vol. 1, p. 493, VCH, Weinheim (1997); c) J.W. Niemantsverdriet, Spectroscopy in Catalysis, p. 167, VCH, Weinheim (2000). 